\title{
A RELAÇÃO ENTRE “DOM/DÍVIDA” E DIREITOS
}

\section{TRABALHISTAS}

\author{
Laura Senna Ferreira*
}

Resumo Este artigo pretende analisar a interface entre direitos trabalhistas e a lógica do "dom" e da "dívida", nas relações de trabalho, em um grupo de oficinas mecânicas da cidade de Pelotas-RS. Nessa perspectiva, o estudo procura reconstruir a história da legislação trabalhista, vinculada à luta dos trabalhadores, e articula a presença de tais direitos com a permanência de determinadas lógicas tradicionais, com base em laços de pessoalidade entre empregados e patrões. Tendo como referência o grupo investigado, analisa, a partir dos anos 1990, de que maneira as transformações advindas da "reestruturação produtiva" impactaram sobre essas relações e, de que forma, sob o ponto de vista dos "direitos", tornou-se cada vez mais insuficiente a dicotomia formalinformal como representação dos arranjos contratuais e das relações de trabalho.

Palavras-chave Direitos trabalhistas; dom e dívida; reestruturação produtiva; oficinas mecânicas.

\section{THE RELATION BETWEEN “GIFT/DEBT” AND LABOR RIGHTS}

Abstract This article intends to analyze the interface between labor rights and the logic of "gift" and "debt" in labor relations within a group of mechanic repair shops, in the city of Pelotas-RS. In this perspective, the study seeks to reconstruct the history of labor legislation, linked to the fight of workers and articulates the presence of these rights to the permanence of a certain traditional logic, based on personal ties between employees and employers. Taking the group surveyed as reference, the work analyzes how the transformations resulting from a "productive restructuring", as from the 9os, has caused an impact on these relations and how, from the point of view

* Doutoranda em Sociologia e Antropologia no PPGSA da Universidade Federal do Rio de Janeiro (UFRJ). 
of "rights", the formal-informal dichotomy has become ever more unsatisfactory, as the representation of contract and labor relation arrangements.

Keywords Labor rights; gift and debt; productive restructuring; repair shops.

\section{INTRODUÇÃo}

A proposta do presente artigo consiste em investigar o segmento das pequenas e médias oficinas mecânicas, sob a ótica da presença/ausência da judicialização das relações de trabalho' ${ }^{1}$. Procura-se, para isso, entender de que maneira, sobretudo a partir da década de 1990, a vinculação das oficinas ao processo de "reestruturação produtiva"2 fragilizou ainda mais uma categoria de trabalhadores que nem ao menos chegou a consolidar seu acesso aos direitos trabalhistas.

Essas oficinas são, em sua maioria, pequenas e médias empresas localizadas no interior do Estado do Rio Grande do Sul, nas quais as relações de trabalho ocorrem em torno de laços de pessoalidade, sendo o recurso à Justiça acionado apenas quando acordos pessoais são rompidos. Em consonância com esse aspecto, pretende-se analisar as dificuldades de existirem formas de contestação em relação a determinadas condições de trabalho, pois, mesmo havendo instâncias organizadas de reivindicação ${ }^{3}$, a maioria dos trabalhadores envolvidos na atividade se encontra na informalidade.

Neste artigo será realizada, em primeiro lugar, uma caracterização do segmento das oficinas mecânicas da cidade de Pelotas-RS. Em seguida, buscar-se-á analisar aspectos da construção da legislação trabalhista brasileira. Abordar-se-á, também, a fragilidade da fronteira teórica e prática entre trabalho formal e informal. Por fim, será feito um esforço no sentido de compreender os motivos que levam, ou não, à reivindicação na Justiça de determinados direitos assegurados em lei.

\section{O SEGMENTO DAS OFICINAS MECÂNICAS}

A partir dos anos 1950, o setor automotivo passou a figurar na "ideologia desenvolvimentista”, que caracterizou o governo de Juscelino Kubitschek (CARDOso,

1 A pesquisa de campo junto às oficinas mecânicas foi realizada na cidade de Pelotas-RS, em 2009/2010. Durante a pesquisa, foram utilizadas entrevistas semiestruturadas (BAUER, 2002) e observações etnográficas (PEIRANO, 1995).

2 Entre os principais autores que estudam o tema da "reestruturação produtiva" no Brasil estão Ramalho (2006) e Antunes (2005).

3 Os mecânicos de reparos de veículos de Pelotas são representados pelo Sindicato dos Trabalhadores nas Indústrias Metalúrgicas, Mecânicas e do Material Elétrico, filiado à CUT. 
1978) como símbolo do desenvolvimento do Brasil, trazendo em si uma "aura de modernidade" (NEGRo, 1999, p. 10).

Essa indústria cresceu de 1950 até 1980, quando ocorreu o esgotamento do modelo "desenvolvimentista" e a ascensão do "Novo Sindicalismo" (RodRIGUes, 1999), levando as empresas a buscarem inovações. Na década de 1980, a qual foi marcada por grande competitividade e pelos movimentos de contestação dos trabalhadores, ocorreram os primeiros passos da "reestruturação produtiva" na indústria automotiva brasileira.

Nesse contexto, o segmento das oficinas mecânicas de automóvel, que faz parte da constituição dessa cadeia, também sentiu as transformações pelas quais passou o setor automobilístico. Os novos modelos de carros desenvolvidos pelas montadoras desencadearam a necessidade de outros saberes e tecnologias de reparos.

Respondendo às demandas mais recentes, as oficinas autorizadas rapidamente se readaptaram aos novos tempos, enquanto os antigos mecânicos, aqueles que surgiram e permaneceram nas margens das montadoras, não tiveram a mesma facilidade. Alguns buscaram absorver diferentes saberes e adotaram novas tecnologias, enquanto outros não tiveram possibilidade de se reestruturarem e acabaram encerrando seus empreendimentos.

Os respectivos indícios indicam, dessa maneira, que os mecânicos, tantos os proprietários quanto os empregados, viram sua trajetória de vida e de trabalho ser amplamente transformada pelas mudanças na indústria automobilística brasileira.

A relação das oficinas com as transformações efetuadas pelas montadoras é permanente. No entanto, não possui poder homogeneizador, posto que as pequenas e médias oficinas continuam bastante heterogêneas. Nesse cenário altamente moderno de reestruturação, vários desses empreendimentos seguem, por exemplo, contando com a presença de familiares, vizinhos e amigos, no mesmo local de trabalho, no qual certo "apadrinhamento", companheirismo e afetividade muito comumente permanecem imbricados ao cotidiano de trabalho.

Nos últimos anos, essas relações que envolvem "lealdade" e "confiança" foram intensamente abaladas, e as dificuldades enfrentadas por algumas oficinas fizeram com que parte dos proprietários deixasse de oferecer certas "benesses", como, por exemplo, casa e alimentação, o que aumentou a condição de vulnerabilidade desses trabalhadores, muitos dos quais possuem apenas vínculos informais de trabalho.

Nesse contexto, a hegemonia das relações de pessoalidade entre proprietários e empregados faz com que, muitas vezes, a lógica das relações fundamentadas na proximidade distancie a possibilidade de reivindicação de direitos. Ao menos que a 
reciprocidade vinculada à lógica do "dom" e da "dívida" " , esperada pelos trabalhadores, seja rompida, pode ser que a busca por direitos na Justiça nunca se efetive.

Observa-se que há, nessas oficinas mecânicas, uma convivência entre relações altamente pessoalizadas e outras circunscritas à objetividade de determinados contratos, indicando, dessa maneira, o quanto o capitalismo contemporâneo, como afirmara Harvey (1992, p. 146), é capaz de conviver com distintos ritmos e intensidades de mudanças.

A seguir, pretende-se demonstrar de que forma as diferentes lógicas, sejam elas familiares, sejam informais, sejam pessoais, relacionam-se, afinam-se e/ou se contradizem, em relação a outras racionalidades fundamentadas na formalidade, na abstração e, principalmente, no Direito moderno.

Com isso, procura-se escapar a qualquer dicotomia entre tradição e modernidade e indicar que as noções do Direito estão presentes e imbricadas com qualquer outra dessas lógicas sociais. Os parâmetros do Direito podem, ou não, ser apropriados pelos atores em jogo, uma vez que esse aspecto depende da particularidade das relações e dos contextos sociais, mas as normas jurídicas fundamentais são conhecidas e reconhecidas por eles.

\section{O RAMO DA MECÂNICA A PARTIR DA PRESENÇA/AUSÊNCIA DOS DIREITOS TRABALHISTAS}

As questões pertinentes a serem refletidas, as quais se referem à relação dos empregados das oficinas mecânicas com os direitos trabalhistas, são as seguintes: se a maioria dos trabalhadores, conforme foi observado, conhece seus direitos, por que deixam de acionar a Justiça quando não recebem essa cobertura? Ou, ao contrário, por que alguns recorrem à instância jurídica, enquanto outros não o fazem?

A fim de encontrar respostas que atendam às indagações formuladas, é preciso entender que, nesse segmento, a maioria dos trabalhadores está na informalidade em termos formais. Apesar da aparente redundância da linguagem, estar na informalidade em termos formais não significa estar em termos reais. Isso ocorre porque, mesmo sem carteira assinada e acesso legal aos direitos, na prática, muitas vezes, estão sendo cumpridos os quesitos fundamentais da legislação trabalhista.

Existem, entre essas oficinas, alguns estabelecimentos em condições bastante precárias. São aqueles cujo proprietário não possui condições objetivas de legalizar

4 A noção de “dom” e "dívida” está vincula à tradição teórica inspirada em Mauss (2003). 
todos os trabalhadores, sob pena de encerrar o próprio empreendimento, mas que, em alguns casos, independentemente disso, acredita que é "justo" fazê-lo e procura estar de acordo, na prática, com aquilo a que os empregados têm direito.

Contrariamente, existem estabelecimentos que possuem condições materiais de legalizar os trabalhadores e que, mesmo assim, não o fazem. Esses parecem ser os maiores alvos de ações na Justiça, posto que os empregados sabem que não se trata de uma impossibilidade real do proprietário, mas de uma vontade de "lucrar mais".

As oficinas nas quais há ausência formal e ausência prática de direitos geralmente são aquelas de "fundo de quintal", nas quais trabalham pessoas da família do dono e, eventualmente, algum amigo ou vizinho. Nessas, geralmente, a questão dos direitos legais não se coloca durante ou após a saída do estabelecimento.

No caso de presença formal e ausência real dos direitos, quer dizer, quando há carteira assinada, e os proprietários não seguem as normas, os empregados estão mais em desacordo com seus patrões, uma vez que, nesses casos, possuem todo o respaldo da lei. A presença formal e a presença real dos direitos são proporcionadas, na maioria das vezes, pelas condições econômicas das oficinas e pelas convicções dos proprietários, muitos deles, há pouco tempo, empregado em alguma oficina mecânica.

Nesse universo, alguns empregadores se queixam da "desconsideração" dos empregados que, depois de trabalharem anos nas oficinas, colocam "questão na Justiça”. Por outro lado, os trabalhadores dizem que o fizeram exatamente por entenderem ser "injusto" não terem acesso aos direitos, depois de estarem tanto tempo no estabelecimento. Mas, além dessa conclusão fundamentada nos anos de serviço, os motivos que fazem com que alguns entrem na Justiça e outros não residem em um terreno mais complexo das relações de "reciprocidade", em termos de "dom e dívida" (MAuss, 2003; Sigaud, 1979), que ocorre entre patrões e trabalhadores.

Nesse sentido, enquanto o empregado considerar justas as atitudes do empregador, sua permanência e saída da oficina apresentarão a tendência de ocorrer sem mediação jurídica. Porém, a partir do momento em que alguma divergência acontecer, seja de ordem econômica, seja de subjetiva, torna-se, frequentemente, um bom motivo para ação na Justiça. Geralmente, alguma atitude considerada como de "ingratidão" do empregador (como, por exemplo, não deixar o funcionário, no momento em que sai da oficina, levar consigo uma ferramenta pela qual tenha apreço) justifica essa atitude de revolta individual do trabalhador. 
Com isso, pretende-se afirmar que existe uma "reciprocidade" fundamentada em certos "costumes" (Thompson, 1998) e expectativas que precisam ser considerados quando a relação acontece com base na pessoalidade. A partir do momento em que essa "racionalidade" não é mantida, tem-se um cenário que potencializa a ação via Sistema Judiciário.

Dessa maneira, não é possível entender as instituições jurídicas inspirando-se apenas em argumentos racionalistas e, muito menos, economicistas, pois os trabalhadores fazem um cálculo que envolve, simultaneamente, diferentes racionalidades. Acionar ou não na Justiça para reivindicar direito é uma opção que parece se colocar apenas quando ocorre uma ruptura em esferas de relações das quais se esperava "lealdade" e "reciprocidade".

A seguir, procura-se historicizar a partir de quando o acesso à Justiça passou a ser uma possibilidade, utilizada ou não pelos trabalhadores. Se alguns dos empregados das mecânicas podem sair da oficina e procurar seus direitos na Justiça, essa alternativa vem sendo gestada há muitas décadas, na sociedade brasileira, na qual uma "cultura de direitos" (Pessanha, 2001) se cristalizou tanto no setor formal quanto no informal do mercado de trabalho.

\section{A CONSTRUÇÃO DA LEGISLAÇÃO TRABALHISTA}

A legislação social que existe no Brasil é, em sua essência, a legislação trabalhista, cuja consolidação se deve a um movimento de muitas lutas dos trabalhadores, considerando que a conquista de direitos foi um processo de décadas de mobilizações e conflitos entre capital e trabalho.

Na prática, como afirmam Murilo (2009) e Santos (1994), os direitos sempre foram seletivos. Santos (1994), por exemplo, observa que, a partir de 1930, mais especificamente, desde a criação do Ministério do Trabalho, Indústria e Comércio, em 1931, e da carteira profissional para trabalhadores urbanos, em 1932, foi dado início àquilo que o autor definiu como uma "cidadania regulada”, ou seja:

[...] são cidadãos todos aqueles membros da comunidade que se encontram localizados em qualquer uma das ocupações reconhecidas e definidas em lei. [...] A cidadania está embutida na profissão e os direitos dos cidadãos restringem-se aos direitos do lugar que ocupa no processo produtivo, tal como reconhecido por lei. Tornam-se pré-cidadãos, assim, todos aqueles cuja ocupação a lei não reconhece (SANTOS, 1994, p. 68). 
Nesse sentido, trabalhadores rurais e urbanos cujas profissões não estivessem regulamentadas eram considerados pré-cidadãos. Nesse momento, a "associação entre cidadania e ocupação proporcionará as condições institucionais para que se inflem, posteriormente, os conceitos de marginalidade e de mercado informal de trabalho" (SAntos, 1994, p. 68). Além disso, a lei de sindicalização estabeleceu, a partir de 1931, quem poderia pertencer ao sindicato, e o funcionamento deste passou a depender de registro no Ministério do Trabalho. Desde então, só puderam apresentar reclamações trabalhistas nas Juntas de Conciliação e Julgamento os empregados sindicalizados. Mais adiante, com a Carta de 1937, a população economicamente ativa foi partilhada de vez entre regulamentados e não regulamentados. Dessa forma:

A regulamentação das profissões, a carteira profissional e o sindicato público definem, assim, os três parâmetros no interior dos quais passa a definir-se a cidadania. Os direitos dos cidadãos são decorrência dos direitos das profissões e as profissões só existem via regulamentação estatal. O instrumento jurídico comprovante do contrato entre o Estado e cidadania regulada é a carteira profissional que se torna, em realidade, mais do que uma evidência trabalhista, uma certidão de nascimento cívico (SANTOS, 1994, p. 69).

O Estado, assim, via profissão, definiu quem era e quem não era cidadão. A prática da regulamentação das profissões passou a ser uma espécie de "batismo cívico" e primeiro passo para o ingresso na cidadania.

As primeiras manifestações de acesso dos trabalhadores a essa "cidadania regulada" podem ser observadas, por exemplo, quando Biavaschi (2007) analisa processos datados entre 1936 e 1942, que giraram em torno da Lei no 62, de 1935, a chamada Lei da Despedida, que garantia estabilidade depois de dez anos de emprego. Essa foi umas das primeiras leis que, segundo a autora, representou a constituição dos trabalhadores como sujeitos de direito.

A partir desse momento, os direitos do trabalho "assumiram posição estratégica para a vivência da cidadania, o que se reforçou pela fragilidade dos direitos civis e pelo desrespeito aos direitos políticos" (CASTRO, 2002, p. 12)5. Da perspectiva

5 Castro (1979) demonstra como, contrariando a sequência que T. H. Marshall, em Cidadania, classe social e status, afirma ser típica do clássico caso inglês: direitos civis no século XVIII, direitos políticos no século XIX e direitos sociais no século XX, no Brasil, o acesso aos direitos sociais, principalmente os do trabalho, veio primeiro. 
de Castro (2002), de modo geral, na sociedade brasileira, falar de uma história dos direitos é falar de uma história das formas de organização dos trabalhadores.

A Primeira República foi o momento inicial das lutas por direitos e pela constituição de uma identidade a partir do trabalho. De acordo com Castro (2002), essa experiência republicana foi camuflada pelo Estado pós-30, para que, assim, o governo do presidente Getúlio Vargas pudesse sustentar a "tese da outorga" dos direitos $^{6}$. A partir da década de 1930, principalmente desde 1937, os "direitos sociais, materializados com destaque nos direitos do trabalho, tornaram-se o centro definidor da condição de cidadania no país" (CASTRo, 2002, p. 34)7.

Castro (2002) ainda afirma que somente com a Constituição de 1988, que incorporou a CLT, os direitos de cidadania foram expandidos para patamares políticos e civis. No entanto, os direitos do trabalho continuaram sendo o centro definidor da noção de cidadania.

Essa questão é um dos principais temas analisados por Paoli (1989). A autora indica que, durante muito tempo, as relações de trabalho na sociedade brasileira foram pautadas por instituições privadas, e o direito de cidadania se manteve privilégio das elites. Apesar de o golpe militar de 1930 ter levado para dentro do Estado as demandas nascidas nas relações de trabalho, após 1937, os patrões se uniram para burlar e limitar os direitos legais dos trabalhadores, fortalecendo seu modelo privatista.

Esse modelo privatista é resquício, como demonstra Sevcenko (1993), ao analisar a Revolta da Vacina, de uma lógica que aboliu a escravidão, mas que não conseguiu deixar de ver o trabalhador como escravo. Conforme Sevcenko (1993, p. 80), aos "pobres, em geral, nessa sociedade, não se atribui a identidade jurídica de cidadãos, inerente à República. Na prática, era reservado a eles um tratamento similar ao dos antigos escravos".

Tal discussão, tendo em vista o caso das pequenas e médias oficinas em análise, nas quais praticamente inexiste organização política e onde predominam vínculos fundamentados em relações de pessoalidades, a partir dos quais qualquer reivindicação é tratada como gesto de "ingratidão" , não é possível pensar em uma relação direta entre lutas e direitos. Poder-se-ia dizer, então, de forma precipitada,

6 Em 1919, uma conferência de Rui Barbosa (1988), intitulada A questão social e política no Brasil, demonstra, segundo Evaristo Moraes (1988), que, além dos trabalhadores, os próprios políticos defendiam formas de proteção aos empregados, muito antes das políticas getulistas, reconhecendo os excessos do sistema liberal.

7 Em 1940, foi instituído o salário-mínimo; em 1941, começou a funcionar a Justiça do Trabalho; em 1943, foi criada a CLT.

8 Ramalho (1989) também indica, em estudo sobre a FNM, que as benesses da empresa, no período em que predominava uma gestão mais personalizada, fizeram qualquer forma de insubordinação 
que, não havendo organização política nem conflitos explícitos, esses sujeitos não teriam consciência de seus direitos. Ocorre que, na prática, a construção da ideia de direito está tão cristalizada e, de certa maneira, é tão legítima entre os trabalhadores da sociedade brasileira que, nos mais diferentes ramos, há uma forte clareza acerca dos direitos trabalhistas.

Um aspecto que evidencia essa referência, no caso em questão, é que, quando se rompe o vínculo de "reciprocidade" que une trabalhadores e proprietários, o recurso à Justiça é frequentemente acionado, o que ocorre tanto entre os trabalhadores formais quanto entre os informais ocupados no setor das oficinas mecânicas.

\section{A FRAGILIDADE DA FRONTEIRA TEÓRICA E PRÁTICA ENTRE TRABALHO FORMAL E INFORMAL}

A questão da tensão entre mercado de trabalho formal e informal é uma problemática clássica na sociologia brasileira. Oliveira (2006), em Crítica à razão dualista, procura superar essa dicotomia e estabelece a interdependência entre essas instâncias. No caso das oficinas mecânicas em análise, é importante observar o quanto o informal, conforme se constatou, tem por referência o mercado de trabalho formal.

Nesses termos, em consonância com as proposições de Noronha (2000; 2003), há, no Brasil, uma forte presença da lei na estruturação do mercado de trabalho, posto que o "próprio mercado informal, de certa forma, se molda pela lei, inspira-se nela” (NoronHA, 2000, p. 242).

Isso significa que mantém normas não escritas, oriundas da CLT, que definem os padrões mínimos do conceito de ser empregado e contam com noções elementares de justiça e contrato justo: "Os contratos informais assalariados urbanos espelham as práticas legais” (Noronha, 2000, p. 272). Por outro lado, afirma Noronha (2000, p. 272):

Os inúmeros casos de desrespeito à legislação do trabalho nas empresas que adotam contratos formais e de "respeito" à lei nas empresas informais mostram a insuficiência da dicotomia formal-informal como descrição dos padrões contratuais ou de relações de trabalho no Brasil.

parecer um ato de "ingratidão" (RAMALHO, 1989, p. 120), dificultando, dessa maneira, formas explícitas de reivindicações dos trabalhadores. 
Conforme o autor, até o final da década de 1980, muitos acreditavam que a informalidade iria ser superada pelo desenvolvimento do país. Contudo, os anos 1990 começaram com uma crescente informalidade, e a "incorporação de diversos segmentos ao mercado formal ainda estava em processo quando 'novas informalidades' surgiram” (NoronHA, 2003, p. 4), o que nunca ocorre sem conflitos, visto que, no "Brasil, a prática de ex-empregados 'informais' processarem seus empregadores quando demitidos exemplifica os limites do acordo 'informal”' (NorONHA, 2003, p. 6).

A percepção do senso comum acerca dos contratos de trabalho pode, popularmente, entender o trabalho informal como justo ou, pelo menos, aceitável. A aceitação requer um piso mínimo de direitos (tais como $13^{\circ}$ salário, vale-transporte e férias anuais) e envolve "uma complexa avaliação que inclui noções de direito, justiça, ética, bem como conveniências pessoais" (NoronHA, 2003, p. 8).

Para o autor,

Um contrato “informal”, verbal, pode ser entendido como "justo" se o empregado percebe que o empregador tem boas razões para não regularizar a situação (por exemplo, uma microempresa em dificuldades financeiras). Ao contrário, quanto mais o trabalhador percebe que a "informalidade" é um meio de gerar um retorno extra para a empresa, mais “injusto” será o contrato (NoronHA, 2003, p. 8).

Na concepção do autor, para compreender os contratos que são inaceitáveis por parte dos trabalhadores, é "essencial a compreensão daquilo que escapa à razão do economista e do jurista, isto é, o balanço efetivamente elaborado pelas partes dos contratos entre as noções de eficiência e justiça” (NorONHA, 2003, p. 10) ${ }^{9}$.

Cardoso (2003) também procura tencionar essa dicotomização entre mercado de trabalho formal e informal e demonstra a ocorrência de uma informalização crescente nas práticas do mercado formal. $\mathrm{O}$ autor parte da evidência de que, nos anos 1990, passa a existir uma judicialização das relações de classe no Brasil, representada por uma explosão de procura ao recurso judiciário, o que ocorre porque:

[...] em modelos legislados de relações de classe como o nosso, o aumento da judicialização é conseqüência natural da deslegitimação da norma legal pelos

9 Na visão de Noronha (2003), o programa neoliberal de desregulamentação, que se esboçou nos anos de 1990, enfrenta o fardo de o Brasil ser um modelo não contratual, e sim legislado, no qual a condição de assalariado é a base da cidadania, e, apesar da informalidade, a lei continua sendo uma referência para as partes. 
capitalistas. Transformações importantes no palco da luta de classes reduziram o poder coercitivo dos sindicatos e a capacidade fiscal do Estado, abrindo caminho para que os empregadores avaliem como pouco custoso evadir-se da norma (CARdoso, 2003, p. 495).

Cardoso argumenta que, desde o início da década de 1990, os “empregadores estão deslegitimando a ordem legal existente [e] flexibilizando a frio mercado de trabalho" (CARDOSo, 2003, p. 496). Conforme o autor, o capitalista faz um cálculo (entre seguir ou não a legislação trabalhista), envolvendo custos e benefícios. E, de fato, são poucos os que concordam moralmente com a norma. Porém, em alguns casos, o próprio ambiente material pode impor limites à adesão à regra, o que ocorre, frequentemente, em comunidades pobres que não permitem nem mesmo "imaginar alternativas ao trabalho informal, de sorte que a relação com a regra simplesmente não se põe: nem trabalhadores, nem empregadores (se houver) tornarão a regra jurídica objeto de suas relações” (CARDOso, 2003, p. 517).

Para Cardoso (2003), é notório que "a economia brasileira tratou de flexibilizar no grito o direito do trabalho nos anos 90, via contestação da norma legal" (CARdoso, 2003, p. 521). Como o modelo é legislado, "o resultado esperado não é outro senão o recurso à justiça” (CARDOSO, 2003, p. 521).

Geralmente as reclamações buscam reparos retroativos, referentes ao tempo em que a pessoa esteve empregada, o que indica uma opção sistemática pela ilegalidade, mas não necessariamente pela informalidade.

Nesse contexto, a Justiça do Trabalho está se tornando o lugar que tenta atenuar os males da perda do emprego. Capital e trabalho, agora, defrontam-se, primordialmente, "pela mediação de advogados e juízes do trabalho, intérpretes do direito" (CARDOSO, 2003, p. 546). Isso ocorre porque os "empregadores podem escolher não cumprir o que a lei prescreve" (CARDOSO; LAGE, 2005, p. 452) e decidir correr o risco de não ser pego pela fiscalização.

Nesse sentido, tendo em vista a noção de mercado formal e informal, "a rigor, nenhum destes termos designa, como nos acostumamos a acreditar, categorias sociais distintas. [...] não denotam mais do que práticas sociais que não são estanques" (Silva, 1990, p. 5).

No caso das oficinas mecânicas em análise, onde muitas vezes o ambiente econômico é pouco favorável, constata-se referência formal e/ou prática à legislação trabalhista, o que indica, como afirma Noronha (2003), a legitimidade da CLT mesmo em setores que frequentemente não estão formalmente de acordo com ela. 
Entre os empregados dessas oficinas, verifica-se que, quando relações de pessoalidade são rompidas, o que muitas vezes ocorre no momento em que o empregado sente que o patrão está "abusando" de sua posição e sendo "injusto", a Justiça do Trabalho entra como recurso, em uma espécie de "acerto de contas". Nesse sentido, pode-se dizer que não há desconhecimento acerca dos direitos por parte desses atores, mas considerações e balanços que levam ou não a reivindicá-los. A tendência de que isso ocorra ou não está relacionada às noções de contrato “justo" e “aceitável” (NoronHA, 2003) construídas por esses sujeitos.

Esses aspectos obrigam a rever a rigidez das fronteiras entre mercado de trabalho informal e formal, posto que o informal também está pautado pela legislação. Além disso, considerando o desrespeito à lei, por intermédio de uma "flexibilização a frio" (CARDOSo, 2003) das relações de trabalho, setores que, anteriormente, estavam no "núcleo duro" (SiLva, 1990) da cidadania perdem direitos e, consequentemente, aproximam-se de setores como o ramo das oficinas em questão, tradicionalmente, marcado por contratos informais.

Com a reformulação neoliberal das instituições trabalhistas, em um momento de enfraquecimento das lutas e limitação das ações dos sindicatos, crescem a informalidade e a precariedade do trabalho (Grillo, 2008). As tendências de "informalização", historicamente presentes, foram reforçadas pela racionalidade econômica da década de 1990. Nesse contexto de desmonte do conjunto normativo e institucional, adquire consistência um verdadeiro despotismo na área econômica, marcada por uma intensa reprivatização das relações de classe e "pela extensão dos contratos ilegais de trabalho a áreas antes imunes a relações informais de emprego" (CARDoso, 1999, apud Grillo, 2008, p. 324).

Nesse caso, a condição hegemônica de informalidade já não é uma particularidade dos trabalhadores sem carteira de trabalho. Dessa maneira, os empregados das oficinas mecânicas e de outros ramos predominantemente informais cada vez mais se parecem com assalariados do setor formal e vice-versa e, assim como esses, frequentemente lançam mão do recurso à Justiça como uma estratégia de contestação e resistência.

\section{OS MOTIVOS QUE (NÃO) LEVAM À PROCURA DOS DIREITOS ASSEGURADOS EM LEIS}

Os trabalhadores empregados nas pequenas e médias oficinas mecânicas conhecem, em sua grande maioria, seus direitos. O fato de não os reivindicar, seja na relação direta com o patrão, seja na Justiça, não indica, necessariamente, falta 
de clareza e/ou informação, mas, antes, uma racionalidade estratégica que avalia as possibilidades de fazer isso ou não.

Nesse sentido, a pesquisa de Sigaud (1979) é extremamente importante. Sigaud (1979) procurou entender, na Zona da Mata de Pernambuco, o significado da ruptura das relações tradicionais que ocorriam em torno da moradia no engenho e a emergência de novas relações entre proprietários e trabalhadores, a partir da “criação dos direitos”. Antes dos “direitos”, o vínculo entre proprietários e moradores era mediado, exclusivamente pelo "dom de um lado e a dívida do outro" (SigaUd, 1979, p. 40) ${ }^{10}$. Conforme Sigaud (1979), nesse universo, mesmo depois da "criação dos direitos", se o proprietário continuasse atuando dentro da lógica do "dom”, o trabalhador não se sentia desejoso de colocar a questão na Justiça.

Grynszpan (1999), assim como Sigaud (1979), traz elementos para pensar a apropriação dos atores em relação aos direitos. Em sua leitura, a legitimidade da instituição judiciária não pode ser considerada como dada; é preciso considerar as noções morais de justiça com as quais os indivíduos operam. Assim, é importante perceber aspectos como:

[...] distintos usos que os indivíduos, em função de seus capitais específicos, de sua posição no espaço social, de suas redes de relações, de alianças e oposições, fazem dos juizados, bem como daquilo que podem perceber e formular, mais do que como um problema, como uma questão passível de uma oficialização, de uma judicialização (GRYNSZPAN, 1999, p. 112).

Os direitos sociais, gestados na modernidade, tiveram o papel de proteger os trabalhadores das adversidades do mercado de trabalho ${ }^{11}$. Segundo Thompson (1998), a estrutura de direitos do trabalho começa a surgir junto à formação da própria classe trabalhadora, no momento em que os "costumes" que garantiam as proteções sociais estavam sendo tencionados.

Para Thompson (1998), bem como para Sigaud (1979), os motivos que fazem com que os trabalhadores reivindiquem direitos estão muito além de um cálculo exclusivamente econômico; existem razões de ordem política e moral que estão em jogo.

10 Essa lógica paternalista tem origem remota na sociedade brasileira. De acordo com Moraes (1980), Jorge Street, por exemplo, defendia o paternalismo e pensava que, em um período intermediário, os patrões precisavam servir de conselheiros e guias para os trabalhadores.

11 Essas questões são intensamente discutidas nas obras de Polanyi (1980) e de Castel (1998). 
Tal aspecto vai ao encontro das afirmações que aqui se fizeram em relação aos mecânicos empregados nas oficinas. Quando eles recorrem à Justiça, estão reconhecendo que a situação de "clandestinos" na qual se encontram não é mais "aceitável”. Isso ocorre, geralmente, nos casos em que deixaram de se sentir dignos em função de algum "abuso" por parte dos patrões.

Quando os empregadores rompem com certa "reciprocidade" que, como destaca Sigaud (1979), está presente em relações personalizadas, os trabalhadores não veem mais razões para cultivar uma "fidelidade”. Poderia ser dito, então, que, quando as expectativas em torno dos "costumes" (THOMPSON, 1998) são rompidas, uma rebeldia se instaura. Nesse caso, o patrão deixa de ser considerado "amigo", e o trabalhador pode "colocar a questão na Justiça", fazendo com que os direitos se tornem objetivamente existentes.

\section{CONSIDERAÇÕES FINAIS}

O que se procurou pensar neste artigo foi quanto à presença e/ou à ausência da legitimidade dos direitos e à possibilidade de reivindicá-los na Justiça, no caso de um grupo de mecânicos da cidade de Pelotas-RS. Constatou-se que, embora a grande maioria seja de trabalhadores não sindicalizados e informais, eles não estão à margem de uma "cultura de direitos" (Pessanha, 2001). Percebeu-se que há entre eles a forte presença da lógica da reciprocidade do "dom" e da "dívida" (Mauss, 2003; Sigaud, 1979), que envolve a relação deles com os proprietários e que faz com que, muitas vezes, o recurso à Justiça se distancie.

No sentido inverso, indicou-se que, quando ocorre uma ruptura nessas expectativas, muitas vezes, o recurso à Justiça se torna uma possibilidade.

Tal discussão se mostrou como fundamental para pensar a fronteira entre o mercado de trabalho formal e informal. Nesse caso, observou-se que, na prática, o informal está, muitas vezes, pautado pelo formal. Na mesma perspectiva, o mercado de trabalho formal, via ilegalidade, pauta-se pela informalidade. No caso em questão, trata-se, muito frequentemente, não apenas de informalidade, mas de uma "ausência presente" das normas jurídicas, ou seja, nas oficinas mecânicas, pode ocorrer uma "ausência" de direitos, no sentido de não serem formalizados, ao mesmo tempo em que pode existir uma "presença" de direitos, no sentido de serem concretizados na prática. 


\section{REFERÊNCIAS BIBLIOGRÁFICAS}

Antunes, Ricardo. Os sentidos do trabalho. Ensaio sobre a afirmação e a negação do trabalho. São Paulo: Boitempo, 2005.

BARbosa, Rui. A questão social e política no Brasil. Conferência pronunciada no teatro lírico. São Paulo: Editora LTr; Rio de Janeiro: Fundação Casa de Rui Barbosa, 1988.

BAUER, Martin et al. A entrevista narrativa. In: BAUER, Martin; GASKEll, George (Org.). Pesquisa qualitativa com texto, imagem e som: um manual prático. Petrópolis: Vozes, 2002.

BiAVASCHI, Magda. O direito do trabalho no Brasil - 1930-1942: a construção do sujeito de direitos trabalhistas. São Paulo: Editora LTr, 2007.

CARDoso, Adalberto. Sindicatos, trabalhadores e a coqueluche neoliberal: a era Vargas acabou? Rio de Janeiro: Fundação Getúlio Vargas, 1999.

Direito do trabalho e relações de classe no Brasil contemporâneo. In: VIANNA,

Luis (Org.). A democracia e os três poderes no Brasil. Belo Horizonte: Editora UFMG;

Rio de Janeiro: IUPERJ/FAPERJ, 2003.

CARdoso, Adalberto; Lage, Telma. A inspeção do trabalho no Brasil. DADOS - Revista de Ciências Sociais, Rio de Janeiro, v. 48, n. 3, p. 451-490, 2005.

CArdoso, Miriam. Ideologia do desenvolvimento - Brasil: JK-JQ. Rio de Janeiro: Paz e Terra, 1978.

CASTEL, Robert. As metamorfoses da questão social: uma crônica do salário. Petrópolis: Vozes, 1998.

CASTRo, Angela. Burguesia e trabalho. Rio de Janeiro: Campus, 1979.

. Cidadania e direitos do trabalho. Rio de Janeiro: Jorge Zahar, 2002.

GRILLO, Sayonara. Relações coletivas de trabalho: configurações institucionais no Brasil Contemporâneo. São Paulo: LTr, 2008.

GrynszPAn, Mario. Acesso e recurso à Justiça no Brasil: algumas questões. In: PANDOLfI, Dulce et al. Cidadania, justiça e violência. Rio de Janeiro: Fundação Getulio Vargas, 1999.

HaRvey, David. A condição pós-moderna. Uma pesquisa sobre as origens da mudança cultural. São Paulo: Loyola, 1992.

Mauss, Marcel. Ensaio sobre a dádiva. In: Mauss, Marcel. Sociologia e antropologia. São Paulo: Cosac \& Naify, 2003.

Moraes, Evaristo. Introdução. In: Moraes, Evaristo. Idéias sociais de Jorge Street. Rio de Janeiro: Fundação Casa Rui Barbosa, 1980. 
Prefácio. In: Barbosa, Rui. A questão social e política no Brasil. Conferência pronunciada no teatro lírico. São Paulo: Editora LTr; Rio de Janeiro: Fundação Casa de Rui Barbosa, 1988.

Murilo, José. Cidadania no Brasil - o longo caminho. Rio de Janeiro: Civilização Brasileira, 2009.

NEgro, Antônio. Nas origens do "Novo Sindicalismo": o maio de 59, 68 e 78 na indústria automobilística. In: RodRigues, Iram (Org.). O Novo Sindicalismo vinte anos depois. Petrópolis: Vozes, 1999.

Noronha, Eduardo. O modelo legislado de relações de trabalho no Brasil. DADOS - Revista de Ciências Sociais, Rio de Janeiro, v. 43, n. 2, p. 241-290, 2000.

Informal, legal, injusto: percepções do mercado de trabalho no Brasil. Revista

Brasileira de Ciências Sociais, São Paulo, v. 18, n. 53, p. 111-129, out. 2003.

Oliveira, Francisco. Crítica à razão dualista - O ornitorrinco. São Paulo: Boitempo, 2006. PAoli, Maria Celia. Trabalhadores e cidadania. Experiência do mundo público na história do Brasil moderno. Estudos Avançados, São Paulo, v. 3, n. 7, p. 40-66, set./dez. 1989. Peirano, Mariza. A favor da etnografia. Rio de Janeiro: Relume-Dumará, 1995.

Pessanha, Elina. Metalúrgicos, sempre operários navais. Da cultura de direitos às perspectivas dos sem-fábricas da indústria naval do Rio de Janeiro. In: Ramalho, José Ricardo; Santana, Marco. Trabalho e tradição sindical no Rio de Janeiro. A trajetória dos metalúrgicos. Rio de Janeiro: DP\&A, 2001.

Polanyi, Karl. A grande transformação - as origens de nossa época. Rio de Janeiro: Campus, 1980.

Ramalho, José Ricardo. Estado-patrão e luta operária: o caso da FNM. Rio de Janeiro: Paz e Terra, 1989.

Dinâmicas sociopolíticas em novos territórios produtivos. In: RAmaLHo, José

Ricardo (Org.). Dossiê: novos espaços industriais e desenvolvimento regional. Cadernos CRH, Salvador/BA, v. 19, n. 46, p. 9-17, jan./abr. 2006.

Rodrigues, Iram. A trajetória do novo sindicalismo. In: Rodrigues, Iram (Org.). O novo sindicalismo vinte anos depois. Petrópolis: Vozes, 1999.

SANTos, Wanderley Guilherme. Cidadania e justiça: A política social na ordem brasileira. Rio de Janeiro: Campus, 1994.

Sevcenko, Nicolau. A Revolta da Vacina: mentes insanas em corpos rebeldes. São Paulo: Scipione, 1993.

Sigaud, Lygia. Os clandestinos e os direitos: estudo sobre trabalhadores da cana-de-açúcar de Pernambuco. São Paulo: Duas Cidades, 1979.

Silva, Luiz Antônio Machado. A (des)organização do trabalho no Brasil urbano. São Paulo em Perspectiva, São Paulo, v. 4, n. 3/4, p. 2-5, jul./dez. 1990.

Thompson, Edward. Costumes em comum. São Paulo: Companhia das Letras, 1998. 